\title{
The Effect of Executive Bonuses and Manager Shareholding Ratio on Corporate Scandals
}

\author{
Yusuke MIYOSHI $^{a^{*}}$, Haruhiko TSUZUKI ${ }^{b}$, Hiroaki ITAKURA ${ }^{c}$ \\ a Advanced Institute of Industrial Technology \\ ${ }^{b}$ The Faculty of Economics, Saga University \\ ${ }^{c}$ Advanced Institute of Industrial Technology
}

\begin{abstract}
This paper analyzes how to suppress the incentive for management to carry out illegal acts through both the number of shareholdings and the compensation agreement. Specifically, if management owns shares beyond the optimal shareholding ratio, corporate scandals can be kept to a minimum. In other words, it is possible to minimize corporate scandals by allocating shares to management. However, in a situation where management owns a lot of shares, it is not possible to maximize the corporate value the owner desires. Thus, in the case where a person with a low shareholding is appointed as top manager, it is better to transfer shares to the top management by stock options etc. than by managers' salaries to discourage illegal acts.
\end{abstract}

Keywords: shareholding ratio, stock options, corporate scandals, executive bonuses

\section{Introduction}

Nowadays, various scandals, such as false statements in securities reports, concealment of automobile recalls, accounting of false statements, etc., are a regular occurrence. Management is in a position to prevent corporate scandals. However, sometimes, managers make strategic management decisions with only private benefits. The Sarbanes-Oxley Act was enforced in the United States and obliged Japan to establish an internal control system based on the Company Law and Financial Instruments and Exchange Act. In addition, companies are working on compliance and CSR to prevent scandals. However, in spite of the enhancement of the system and education on compliance awareness, malicious corporate scandals have continued.

This suggests that corporate scandals tend to be organizational and that they are undertaken for the benefit of the company rather than for individuals. James Reason (2008), for instance, brings up the "Swiss cheese" model, which assumes that everyone makes mistakes and mistakes at certain frequencies are inevitable. There is more than one "hole" (mistake). Some holes (mistakes) might be a result of actions of personnel while other holes derive from the workplace conditions. Therefore, corporate scandals can be understood as being caused by actions taken as part of activities involving the entire organization rather than personal activities.

Many of the studies that explain corporate value from the viewpoint of corporate governance have focused on

*Corresponding author: miyoshi-yusuke@aiit.ac.jp management's share holdings. Jensen and Meckling (1976), Lichtenberg and Pushner (1994), Morck, Shleifer, and Vishny (1989), and Cho (1998) emphasize that the greater the number of shares owned by managers, the stronger the commitment between management and shareholders, resulting in a positive influence on corporate value. According to Kaplan (1994), even when the management ownership ratio is small, officers are dispatched from corporate major shareholders or main banks that have a positive influence on corporate value. However, they say that increasing the shareholding ratio of managers contributes to corporate value, but they do not consider the possibility that management will improve performance through illegal activities. In other words, they do not mention the causal relation between the deviation and the manager's shareholding ratio.

In addition, many studies have pointed out that corporate performance improves when managers receive performance-based salaries. For example, Holmstrom (1982) suggested that linking management salaries to ex-post corporate performance results reduces agency costs between managers and shareholders. However, in the US in the 1980s, Jensen and Murphy (1990) showed that executive salaries were not linked to performance or share price. Therefore, they insisted that executive compensation does not demonstrate the capabilities of management fully. Shleifer and Vishny (1989) showed that entrenchment effects will appear when managers are in conflict of interest with shareholders.

According to Kaplan (2013), the executive salaries of Japanese companies are lower than in Europe or the 
United States. Murase (1998) showed that in companies with a high shareholding ratio of financial institutions, executive bonuses are likely to be cut when corporate performance is "in the red."

According to the report of the Japan Association of Corporate Directors (2013), a strong positive correlation between corporate performance and management fee has been confirmed, but Kato (1997) and Abe et al.(2005) asserted that in Japanese companies, monitoring by financial institutions provides works on corporate performance effectively, and the presence of officers dispatched from banks has pushed down management's compensation. Thus, to increase corporate performance, the mainstream argument was it is necessary to strengthen monitoring from the outside rather than using incentives by way of managers' compensation.

In the United States, the disclosure of management compensation was obliged by the SEC in 1992 and does not allow compensation as company expenses if the annual salary exceeds 1 million US dollars and is not linked to performance. However, legal restrictions are not imposed on the content and level of executive salaries for Japanese companies. In 2005, the Japan Association of Corporate Directors announced guidelines on management compensation and has been working on preparing provisions to pay executive salaries based on corporate performance. In response to this movement, the following was added to the draft of the corporate governance code of the Financial Services Agency: "In order to enable management to demonstrate entrepreneurial spirit, we should reflect long-term corporate performance and latent risk in management's compensation."

However, previous studies have not taken into consideration the fact that the incentive for managers' illegal activities influences the management strategy of the company and that the performance of the company changes through such influence. In addition, regarding the top management's taking illegal activities, there has been no discussion so far from the view of the relation to the stock price recovery and management's ownership percentage.

In this research, we analyzed how to suppress the incentive for management to carry out illegal acts through both the number of shareholdings and individual compensation agreements. Focusing on the agency problem caused by information asymmetry between shareholders and management, we succeeded in presenting institutional design of what kind of contract is required to prevent management from sacrificing the interests of shareholders. Compared with executive compensation, we can expect to prevent scandals by increasing the number of shares owned by management.

Specifically, if the management owns shares beyond the optimal shareholding ratio, corporate scandals can be kept to a minimum. In other words, it is possible to minimize corporate scandals by giving shares to management.
However, in a situation where management owns a lot of shares, it is not possible to maximize the corporate value the owner desires. Thus, in the case where a person with a low shareholding is appointed to the top manager, it is better to transfer shares to the top management by stock options etc. than to managers' salaries to discourage illegal acts.

\section{Management and major shareholders model}

In this study, we refer to the setting of the theoretical model of Garoupa (2000). We built a model taking into consideration losses (punishment) through falling stock prices and stock options. In our model, stock options are not included. Rather, we assume management that holds shares to some extent. Of course, if a is assumed to be zero, we can think that it is a salaried worker. In addition, Garoupa (2000) used a linear production function $\alpha(m+n)$, which is the sum of legal activity $(m)$ and illegal activity $(n)$. However, we relax the linear condition and take it as a production function of general type $G(m+n)$. Furthermore, we succeeded in interpreting the shareholding ratio $(\alpha)$ as the bargaining power.

In this paper, we analyze the impact of stock options and executive bonuses that have not been discussed so far regarding scandals. In other words, by delegating management to shareholders with a high shareholding ratio, it is possible to prevent corporate scandals. Scandals are not discovered at the time of receiving director bonuses. Therefore, it depends only on $G(m+n)$ without being negatively affected by damage corporate $\operatorname{value}(\tau)$. In other words, it is proportional to $G(m+n)$.

Here, we assume the existence of shareholders $A$ and manager B. We consider a model where companies cause scandals. The owner tries to control the behavior of management through the shareholding ratio. Suppose the stock price of a company depends on two endogenous variables: legal activities $(m>0)$ and illegal activities $(n>$ $0)$. In this case, the acting owner is informed of illegal activities (e.g., granting of profits, accounting of fancy items, etc.) $G(m+n)$. Here, the increasing functions $m$ and $n$, and the following are assumed: $G_{m}=G_{n}=G^{\prime}>0$ and $G_{m m}=G_{m n}=G_{n n}=G^{\prime \prime}<0$.

In addition, let $E(n)$ be the profit (private benefit) of the manager obtained by illegal activities. This represents the benefit of the manager who improperly gained through illegal acts. For $E(n)$, we make the following assumptions: $E_{n}>0$ and $E_{n n}<0$.

Next, the cost for management to do activities shall be taken. Then, we make the following assumptions: 
$C_{n}, C_{m}>0, C_{m m}, C_{n n}, C_{m n}>0, C_{m m}, C_{n n}>C_{m n}$. This guarantees that $C$ is a strictly convex function. It is also assumed that $E_{n}$ is larger than $C_{n}, C_{m}$. Previous research, such as Osano (2006), has shown that in the event of a scandal, the stock price of many companies (about $80 \%$ ) will recover afterwards. However, these companies incur unrecoverable damage with a probability of about $20 \%$. Thus, we assume the probability $P(n)$ that stock price will not recover due to the occurrence of scandal and damage by value $\tau$. Here, $\tau$ is a sufficiently large value and we assume $P_{n}>0, P_{n n}>0$. In other words, it is assumed that the probability that the stock price will not recover due to the increase in tort is rising rapidly.

In the event that damage to the stock price occurs, our model maintains that shareholders, including the manager, suffer loss in the form of impairment of the value of the holding.

The executive compensation $\omega$ paid to the manager shall be taken. Let the executive compensation $\omega$ paid to the manager be a constant independent of corporate performance.

Let $U$ be the manager's expected utility as expressed by Eq. (1):

$$
U=\alpha\{G(m+n)-\tau P(n)\}+E(n)-C(m, n)+\omega .
$$

If the stock price becomes irrecoverable due to scandal, it will suffer disadvantages. We consider the optimum behavior of management in this model.

The first-order condition of management that maximizes $U$ is described by Eqs. (2) and (3):

$$
\begin{aligned}
& U_{m}=\alpha G^{\prime}-C_{m}=0 . \\
& U_{n}=\alpha\left\{G^{\prime}-\tau P_{n}\right\}+E_{n}-C_{n}=0 .
\end{aligned}
$$

The second-order condition is described by Eqs. (4)-(6):

$U_{m m}=\alpha G^{\prime \prime}-C_{m m}<0$.

$U_{n n}=\alpha\left\{G^{\prime \prime}-\tau P_{n n}\right\}-C_{n n}+E_{n n}<0$.

$U_{m m} U_{n n}-U_{m n}{ }^{2}$

$$
=\left\{\alpha G^{\prime \prime}-C_{m m}\right\}\left\{\alpha G^{\prime \prime}-\alpha \tau P_{n n}-C_{n n}+E_{n n}\right\}
$$

$$
-\left\{\alpha G^{\prime \prime}-C_{m n}\right\}^{2}
$$

$=-C_{m n}{ }^{2}+C_{m m} C_{n n}-C_{m m} E_{n n}$

$$
-\alpha C_{m m} G^{\prime \prime}+2 \alpha C_{m n} G^{\prime \prime}-\alpha C_{n n} G^{\prime \prime}
$$$$
+\alpha E_{n n} G^{\prime \prime}+\tau\left(\alpha C_{m m} P_{n n}-\alpha^{2} P_{n n} G^{\prime \prime}\right)
$$

$>0$.
These three second-order conditions are always satisfied assuming that $\boldsymbol{\tau}$ is large. Therefore, the optimal actions $m$ and $n$ of management are determined by internal solutions as in Eqs. (7) and (8), respectively.

\section{Let $A$}

$$
\begin{aligned}
&=-C_{m n}{ }^{2}+C_{m m} C_{n n}-C_{m m} E_{n n}-\alpha C_{m m} G^{\prime \prime} \\
&+2 \alpha C_{m n} G^{\prime \prime}-\alpha C_{n n} G^{\prime \prime}+\alpha E_{n n} G^{\prime \prime} \\
&+\tau\left(\alpha C_{m m} P_{n n}-\alpha^{2} P_{n n} G^{\prime \prime}\right) . \\
& m_{\alpha}= \frac{1}{A}\left\{-C_{m n} G^{\prime}+C_{n n} G^{\prime}-E_{n n} G^{\prime}\right. \\
&\left.+\tau\left(C_{m n} P_{n}+\alpha P_{n n} G^{\prime}-\alpha P_{n} G^{\prime \prime}\right)\right\} . \\
& n_{\alpha}=\frac{1}{A}\left\{C_{m m} G^{\prime}-C_{m n} G^{\prime}+\tau\left(-C_{m m} P_{n}+\alpha P_{n} G^{\prime \prime}\right)\right\} .
\end{aligned}
$$

From this, it can be seen that if $\tau$ is sufficiently large, then, $m_{\alpha}>0, n_{\alpha}<0$. In other words, the more the management ownership ratio is increased, the more lawful activity $m$ will be increased and the tort of offense $n$ will be reduced.

Equations (7) and (8) show that the shareholding ratio of management greatly affects both the legitimate and illegal activities of management. Here, it is meant that management does not pursue only their own private benefit $E(n)$, meaning that moral hazard in the usual sense does not occur as shown in Eq. (9):

$$
\begin{aligned}
& m_{\alpha}+n_{\alpha} \\
= & \frac{1}{A}\left\{\left(-2 C_{m n}+C_{m m}+C_{n n}-E_{n n}\right) G^{\prime}\right. \\
& \left.+\tau\left(C_{m n} P_{n}-C_{m m} P_{n}+\alpha P_{n n} G^{\prime}\right)\right\} .
\end{aligned}
$$

Because the numerat $m_{\alpha}+n_{\alpha}$ is not always positive, it is not guaranteed that is positive. In other words, an increase in the shareholding ratio of management does not necessarily lead to an increase in corporate value.

Next, let managers' executive compensation be dependent on corporate performance. In other words, executive compensation is $\omega G(m+n), \omega>0$ as in Eq. (10):

$$
\begin{aligned}
U^{\prime}= & \alpha\{G(m+n)-\tau P(n)\} \\
& +E(n)-C(m, n)+\omega G(m+n) .
\end{aligned}
$$

Equations (11) and (12) describe the first-order conditions of management that maximize $U^{\prime}$ :

$$
U_{m}^{\prime}=\alpha G^{\prime}-C_{m}+\omega G^{\prime}=0
$$


$U_{n}^{\prime}=\alpha\left\{G^{\prime}-\tau P_{n}\right\}+E_{n}-C_{n}+\omega G^{\prime}=0$.

Let $B$

$$
\begin{aligned}
= & -C_{m n}^{2}+C_{m m} C_{n n}-C_{m m} E_{n n} \\
& +\left(-\alpha C_{m m}+2 \alpha C_{m n}-\alpha C_{n n}+\alpha E_{n n}\right. \\
& \left.-\omega C_{m m}+2 \omega C_{m n}-\omega C_{n n}+\omega E_{n n}\right) G^{\prime \prime} \\
& +\tau\left(\alpha C_{m m} P_{n n}+\left(-\alpha^{2} P_{n n}-\alpha \omega P_{n n}\right) G^{\prime \prime}\right) . \\
m_{\omega}= & \frac{1}{B}\left\{-C_{m n} G+C_{n n} G-E_{n n} G+\tau\left(C_{m n} P_{n}+\alpha P_{n n} G-\alpha P_{n} G^{\prime}\right)\right\} . \\
n_{\omega}= & \frac{1}{B}\left\{-C_{m n} G^{\prime}+C_{m m} G^{\prime}\right\} .
\end{aligned}
$$

From this, $m_{\omega}>0, n_{\omega}>0$; i.e., the more the management ownership ratio is increased, the more lawful activity $m$ and illegal activity $n$ will be increased as in Eq. (15):

$$
\begin{aligned}
m_{\omega}+n_{\omega}=\frac{1}{B} & \left\{-2 C_{m n} G^{\prime}+C_{m m} G^{\prime}+C_{n n} G^{\prime}-E_{n n} G^{\prime}\right. \\
& \left.+\tau\left(C_{m n} P_{n}+\alpha P_{n n} G^{\prime}-\alpha P_{n} G^{\prime \prime}\right)\right\} .
\end{aligned}
$$

Because $m_{\omega}+n_{\omega}$ is positive, an increase of executive compensation that is dependent on corporate performance leads to an increase in corporate value.

From the above model analysis, we can present the following propositions.

- Proposition 1. It is unknown whether management's increase in ownership is effective in increasing corporate value (negative possibility extremely high).

- Proposition 2. Increase in ownership by managers reduces scandals.

- Proposition 3. An increase in bonuses linked to performance will increase corporate value $G$.

- Proposition 4. An increase in performance-based bonuses to managers increases scandals ${ }^{1}$.

The optimal shareholding ratio of managers who keep scandals to a minimum is different from the optimal shareholding ratio that maximizes corporate performance.

\footnotetext{
${ }^{1}$ Nowadays, mass media have reported Nissan scandals as a violation of the Financial Instruments and Exchange Act, but the top managers have an incentive to describe the amount less than the actual payment amount in the securities report.
}

\section{Conclusion}

From this analysis, we find that if the firm wants to improve corporate performance, it is advisable to pay higher salaries to executives. However, if the firm wants to keep scandals to a minimum, it should give shares rather than higher salaries. It is also necessary to provide shareholders with an awareness of compliance and to promote corporate social responsibility, where corporate scandals will not be tolerated. We find that a company can withstand a scandal if the shareholding ratio of management is not high. For top managers to refrain from illegal acts, it is better to have their own shares held by management. For example, regarding long-term incentives, such as stock options, it can be expected that by increasing the shareholding ratio of management by utilizing the 1 yen stock option, it is possible to reduce the illegal activities of top management. In the background, we can infer that major shareholders may tolerate the top management's illegal activities unless the company raises performance and the stock price drops sharply. In other words, even if a penalty is given to management, scandals will not decrease.

Therefore, the possibility that Propositions 1-4 are established is sufficiently high. We cannot expect to prevent management scandals by increasing top managers' compensation.

As you can see from the propositions 1 to 4 , an increase in performance-based bonuses to managers can increase scandals.

On the other hand, an increase in the shareholding ratio reduces corporate scandals, but does not lead to an increase in corporate value.

According to the report of the Japan Audit \& Supervisory Board Members Association (2018), it has been pointed out that there are many opinions in the practical society that monitoring of top management is important to prevent corporate scandals.

But Admati et al.(1994) point out, it is impossible to monitor managers other than stockholders who can benefit more than monitoring costs and it is institutional difficult to change the ownership of management.

If you respect the results of the questionnaire for top management monitoring, you will need to have major shareholders in order to monitor the top management.

Acknowledgements; We have received some financial support from the Grants-in-Aid for Scientific Research (KAKENHI:26380466,17K03932,19K01860), the ISHII MEMORIAL SECURITIES RESEARCH PROMOTION FOUNDATIO, and the Research Foundation of Nomura School of Advanced Management. 


\section{References}

[1] N. Abe, N. N. Gaston, and K. Kubo: Executive pay in Japan: the role of bank-appointed monitors and the Main Bank relationship, Japan and the World Economy, 17, 371-394, 2005

[2] A. R. Admati, P. Pfreiderer, and J. Zechner : Large Shareholder Activism, Risk Sharing, and Financial Market Equilibrium, Journal of Political Economy, 102, 1097-1130 1994

[3] M-H. Cho: Ownership Structure, Investment, and the Corporate Value: an Empirical Analysis, Journal of Financial Economics, 7, 103-121, 1998

[4] N. Garoupa: Corporate criminal law and organization incentives: a managerial perspective, Managerial and Decision Economics, 21, 243-252, 2000

[5] B. Holmstrom: Moral Hazard in Teams, The Bell Journal of Economics, 13, 324-340, 1982

[6] M. C. Jensen and W. H. Meckling: Theory of the firm: managerial behavior, agency costs and ownership structure, Journal of Financial Economics, 3, 305-360, 1976

[7] M. C. Jensen and K. J. Murphy: Performance Pay and Top-Management Incentives, Journal of Political Economy, 98, 225-264, 1990

[8] S. N. Kaplan: Top Executive Rewards and Firm Performance: A Comparison of Japan and the United States, Journal of Political Economy, 102, 510-546, 1994

[9] S. N. Kaplan: CEO pay and corporate governance in the U.S.: Perceptions, Fact, and Challenges, Journal of Applied Corporate Finance, 25, 8-25, 2013

[10] T. Kato: Chief executive compensation and corporate groups in Japan: New evidence from micro data, International Journal of Industrial Organization, 15, 455-467, 1997

[11] F. R. Lichtenberg and G. M. Pushner: Ownership Structure and Corporate Performance in Japan, Japan and the World Economy, 6, 305-360, 1994

[12] Y. Miyoshi and H. Tsuzuki: Effect of Executives' Shareholding Ratio on Corporate Scandal Prevention, Economic Analysis, Economic and Social Research Institute, Cabinet Office, Government of Japan, 187, 22-46, 2013

[13] R. Morck and M. Nakamura: Banks and Corporate Control in Japan, Journal of Finance, 54, 319-339, 1999

[14] R. Morck, A. Shleifer, and V. Robert : Management Ownership and Market Valuation: An Empirical Analysis, Journal of Financial Economics, 20, 293-315, 1988

[15] H. Murase: Equity Ownership and the Determination of Managers' Bonuses in Japanese Firms, Japan and the World Economy, 10, 321-331, 1998

[16] J. Reason: The Human Contribution Unsafe Acts:
Accidents and Heroic Recoveries (CRC Press, 310 pages).

[17] A. Shleifer and R. W. Vishny: Management entrenchment: the case of manager-specific investments, Journal of Financial Economics, 25, 123-139, 1989

[18] The Japan Association of Corporate Directors : Prevention of Corporate Scandals and the role of Corporate Auditors, 2013

[19] The Japan Audit \& Supervisory Board Members Association : Prevention of Corporate Misconduct and Corporate Auditors' Efforts - Based on analysis of recent corporate scandals and questionnaire results -, 2018 